ISSN electrónico: 2172-9077

DOI: https://doi.org/10.14201/fjc201919183204

\title{
LAS MINORÍAS SEXUALES EN EL CINE DOCUMENTAL ARGENTINO RECIENTE
}

\section{Sexual Minorities in Recent Argentine Documentary Film}

\author{
Dr. Pablo LANZA \\ Universidad de Buenos Aires, Profesor Ayudante Doctor, Argentina \\ E-mail: pablolanza84@gmail.com
}

Fecha de recepción del artículo: 14/04/2019

Fecha de aceptación definitiva: 23/10/2019

\begin{abstract}
RESUMEN
El cine argentino consignó a un lugar marginal la representación de las sexualidades disidentes durante gran parte de su historia. A partir de los primeros años del siglo XXI, estas historias comenzaron a tomar protagonismo en múltiples films, especialmente en el campo documental. Dicho cambio tomó lugar en paralelo a las luchas por los derechos civiles emprendidos por múltiples colectivos y asociaciones, iniciadas con las Marchas del orgullo en 1992 y que culminaron con la aprobación de la Ley de Identidad de Género en el año 2012. En este trabajo nos proponemos analizar un conjunto de documentales rastreando las formas en las que evolucionó la representación de estos personajes: un tránsito que va de la visibilización a la asunción de la lucha para finalizar con el cuestionamiento del concepto mismo de la identidad.
\end{abstract}

Palabras clave: documental; representación; personajes; identidades: performatividad

\begin{abstract}
Argentine cinema consigned to a marginal place the representation of dissident sexualities during most of its history. From the first years of the 21st century, these stories began to take center stage in multiple films, especially within the documentary genre. This change took place in parallel to the struggles for civil rights undertaken by multiple groups and associations, initiated with the first Pride March in 1992 and culminating with the approval of the Gender Identity Law in 2012. In this work, we propose to analyze a body of documentaries focusing on the ways in which the representation of these characters evolved: a transition which began with the visibility of the collectives to the assumption of the struggle and ends with the questioning of the very concept of identity.
\end{abstract}

Key words: documentary, representation, characters, identities, performativity.

\section{Introducción}

Una de las temáticas recurrentes de la historia del cine documental ha sido la representación de minorías y sectores oprimidos, y el caso argentino no es una excepción. Si 
bien las denuncias sobre múltiples sectores sojuzgados ha sido una constante a partir de la experiencia de la Escuela de Santa Fe en los años sesenta, los documentales sobre minorías tomaron un gran impulso particularmente a partir del 2000, momento que supone un importante aumento de la producción de no ficción. A través de distintas modalidades del documental, podemos encontrar films que retratan a diversas minorías: la religión judía, la cultura negra, los inmigrantes y pueblos originarios. En este artículo nos ocuparemos de la representación de las minorías sexuales en el documental argentino, grupos que no contaron con visibilidad desde el punto de vista social y político hasta las últimas décadas, aspecto que se vio reflejado tanto en el cine ficcional como en el documental ${ }^{1}$. El motivo más sencillo que permite explicar esto tiene que ver con que el cine documental en la Argentina ha puesto siempre el foco en la política y la denuncia, y justamente las demandas y luchas de las organizaciones por los derechos homosexuales, como el caso del pionero Frente de Liberación Homosexual de la Argentina durante los setenta, fueron repudiados tanto por parte de la sociedad como de las agrupaciones revolucionarias de aquella época.

La conformación del movimiento de la diversidad sexual en Argentina suele datarse a principios de los años noventa, hecho que muchos autores relacionan con la Marcha del Orgullo LGBTIQ de Buenos Aires, la cual comienza a practicarse en 1992 como principal estrategia de visibilidad (Bellucci y Rapisardi, 1999; Moreno, 2008, Settanni, 2013). Sin embargo, este movimiento contó con algunos importantes antecedentes históricos en la lucha por la diversidad sexual: el primer intento de organización de los colectivos homosexuales lo constituyó el Grupo Nuestro Mundo (1969), que se fusionó en 1971 con un conjunto de intelectuales gay, entre ellos los sociólogos Néstor Perlongher y Juan José Sebreli, para crear el Frente de Liberación Homosexual (FLH). El Frente surgió en un fuerte clima de politización, pero las reivindicaciones perseguidas por las organizaciones guerrilleras eran sociales y «los homosexuales no entraban en los puntos de vista de los intereses superiores de la revolución" (Bazán, 2010, p. 359); cuestión remarcada por la Juventud Peronista y un famoso cartel con el que señalaban su rechazo a la agrupación: «No somos putos, no somos faloperos». El mismo Perlongher resumió, tiempo después, la experiencia del FLH argentino como «un fracaso. No consiguió imponer una sola de sus consignas, ni interesar a ningún sector trascendente en la problemática de la represión sexual, ni -tampoco- concientizar a la comunidad gay argentina" (Perlongher, 2008, p. 83). El retorno de la democracia en 1983 marcó el comienzo de «un proceso de liberalización de los discursos y las prácticas relativos a la sexualidad en Argentina» (Moreno, 2008, p. 220). En estos años cobraron notoriedad en el under teatral figuras como Alejandro Urdapilleta, Humberto Tortonese y Batato Barea, quienes desde el transformismo comenzaron a difuminar las fronteras de los géneros. En 1984 se creó la Comunidad Homosexual Argentina

1. En el cine de ficción la homosexualidad masculina contó con cierta presencia que fue mutando: durante la etapa clásica se trataba de personajes secundarios que tenían una mera función humorística y no asumían su sexualidad de forma explícita, sino que eran considerados raros ofreaks, mientras que a partir de los años sesenta comienzan a ser objeto de abuso en las comedias de los capo cómicos del humor. La homosexualidad en la ficción asumiría un lugar protagónico en un par de melodramas en la década del ochenta: Adiós, Roberto (Enrique Dawi, 1984) y Otra historia de amor (Américo Ortiz de Zárate, 1986), realizados en los primeros años de democracia. En el libro Otras historias de amor, compilado por Adrián Melo (2008), se puede encontrar un listado de las películas de ficción del período 1933-2006 que incluyen a personajes gay. 
(CHA), una de las principales organizaciones que continúa funcionando en la actualidad. Es, entonces, en los noventa que se comenzaron a implementar las "políticas de la visibilidad", tales como la Marcha del orgullo, las cuales se reflejaron tanto en el espacio público como mediático. Este proceso de visibilización y reclamo persiguió el ingreso en la sociedad de estas minorías, aspecto que se diferencia de las experiencias de los setenta en las que "la propia opción sexual era un modo de oponerse a la perpetuación de la sociedad en todos los sentidos posibles, allí donde la liberación sexual era a la vez parte de un proceso político y social emancipatorio» (Bernini, Goggi y Schwarzböck, 2008, p. 189). Las luchas sociales emprendidas durante este período culminaron con la aprobación de la Ley de matrimonio igualitario en 2010, que permitió el matrimonio entre personas del mismo sexo, y la Ley de identidad de género, sancionada en 2012, que posibilitó la inscripción de personas trans con el nombre y sexo de su elección.

En el campo cinematográfico este proceso de visibilización encuentra un paralelo con la producción de los primeros documentales sobre la temática a comienzos del milenio y la creación de festivales como el Diversa Festival Internacional de Cine Gay, Lésbico, y Trans de Argentina (2004-2010) y el Festival Asterisco de temática LGBTIQ (lesbianas, gays, bisexuales, trans, intersexuales, queers) que desde el año 2014 se hizo eco de los postulados del Diversa.

El abordaje del corpus escogido gira alrededor de dos tensiones en la representación de sus personajes: la primera en relación con el público al que se dirige, la cual se dirime en torno a qué elementos enfatizar en su representación, aquellos que los diferencian o asemejan a la norma; y una segunda que busca reflexionar sobre la identidad como un constructo social. Para el desarrollo del artículo hemos dividido al corpus en tres grupos: el primero tiende a trabajar sobre temáticas generales, en las que las historias de vida individuales son presentadas mediante testimonios y funcionan como ejemplos a modo de ilustración; el segundo resalta la militancia que asumen las travestis para lograr ser reconocidas por la sociedad; y un tercero en el que podemos observar un énfasis de los elementos performativos de los personajes (y de los documentales en general) con el objetivo de señalar la construcción de la identidad.

\section{Abogando por la igualdad: testimonios y emotividad}

Este primer conjunto de documentales se organiza principalmente sobre historias de vida y denuncian la posición que la sociedad les otorga a las minorías mediante el recurso del testimonio resaltando el componente emotivo de los relatos. Se trata de películas que abogan por la igualdad pero que, por la misma elección del tema, tienden a compartimentar sectariamente un grupo, generando una suerte de paradoja.

Lesbianas de Buenos Aires (Santiago García, 2004) posee el honor de ser el primer largometraje de la historia del documental argentino que pone como temática central la homosexualidad. En este sentido no resulta sorprendente que su objetivo -a la vez que su mayor mérito- consista en otorgarle visibilidad a este colectivo. Realizado por el crítico de cine Santiago García, el documental busca reducir las características que diferencian a esta minoría acentuando sus similitudes a través de la puesta en escena de actividades cotidianas y testimonios donde relatan distintos aspectos de su vida. La primera estrategia adoptada para lograr tal objetivo es una organización categórica: 
se les otorga una presencia exclusiva a las lesbianas, las "otras", ya que a lo largo del film no aparecen más testimonios que los de las protagonistas, incluso la presencia del director es borrada (casi) de forma total del campo visual. Lesbianas de Buenos Aires no presenta una narración en torno a un conflicto central, sino que se organiza alrededor de la discusión de ciertos tópicos como la diferencia de género, las primeras relaciones sentimentales, la vida en pareja, la maternidad, etc. Los personajes son caracterizados entonces en relación con las historias que cuentan, los ambientes que ocupan y la puesta en escena.

El sistema de personajes se construye alrededor de la oposición entre una protagonista central (Mónica Santino) y distintos grupos de personajes. García resalta a su protagonista del resto a través del tiempo otorgado en campo y su peso dramático, el uso de múltiples locaciones (de las cuales se deduce una mayor dedicación durante el rodaje), la puesta en escena y un posicionamiento estratégico, concediéndole el inicio y la clausura del film. Lesbianas de Buenos Aires abre con una imagen cargada de dramatismo: un primer plano de Mónica en una estación de trenes, el cual pasa en dirección contraria a la de su mirada (fig. 1). Dicha composición presenta a un personaje en tensión con el ambiente que la rodea, pero estoico, casi heroico, el aspecto principal que la caracteriza. En una escena cerca del final, Mónica es retratada en el estadio del Club Atlético Vélez Sarsfield, que se encuentra vacío, mediante un marcado contrapicado a la vez que pasa una gigantesca nube (fig. 2). Según el director, «es un decorado perfecto. Yo veía a Mónica Santino con tanta grandeza que quería darle un paisaje igual de grande y de imponente. Ella tiene un carisma cinematográfico increíble, es alguien que se impone naturalmente»(Villegas, 2004, p. 25).

\section{Fig. 1 y 2: Lesbianas de Buenos Aires}
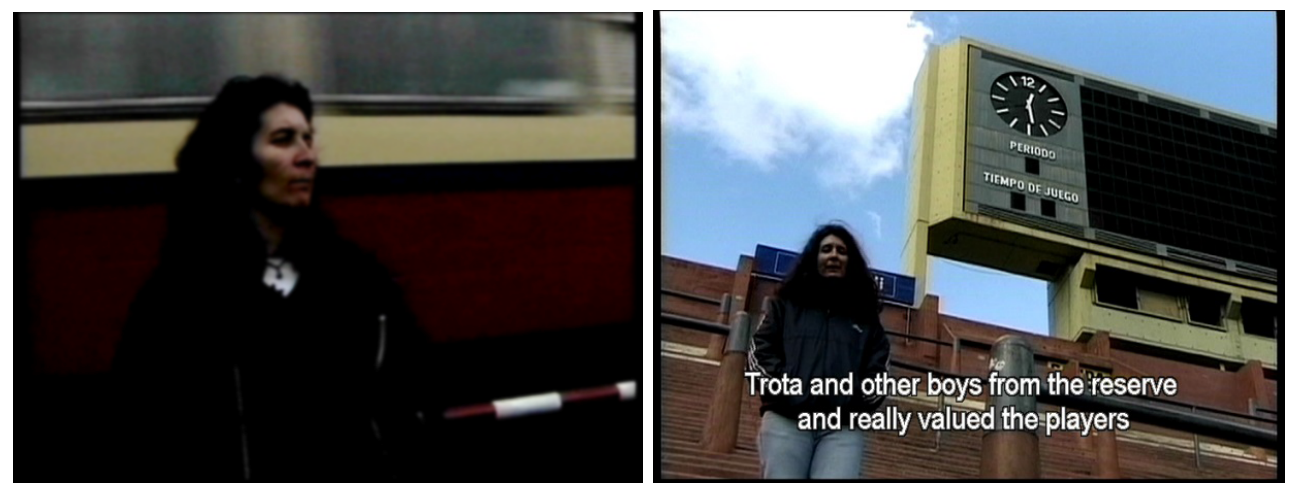

En contraposición a Mónica, el resto de las testimoniantes son presentadas en grupos o en parejas en ámbitos cotidianos. En líneas generales los testimonios de estos personajes secundarios se desarrollan en una única locación, como el caso de la pareja embarazada que relata la espera de su hijo ubicadas en el sillón de su casa o un par de intelectuales que teorizan brevemente sobre la invisibilidad de la que son víctimas².

2. Al respecto de esta invisibilidad, uno de los momentos más logrados del film toma lugar durante una entrevista a Mónica en la calle en la que, mientras se refiere a este tópico, un hombre pasa por delante de la cámara sin reconocer su presencia. 
La otra protagonista del documental es Claudia Castro, quien provee el mayor contrapunto con Mónica, a la vez que el centro emocional del documental hacia el final del film cuando relata la reconciliación con su padre. En esta larga escena, Claudia cuenta para la cámara, ubicaba en un sillón, el momento en que recuperó la relación con su padre, quien le retiró la palabra durante años tras conocer su orientación sexual. Después de retomar paulatinamente la relación con su madre, finalmente decide un día llevar a la casa a su pareja (María Rachid, activista LGBT y futura vicepresidenta del INADI), ${ }^{3}$ quien tras una breve conversación con el padre logra que se sienten todos juntos a comer. García interrumpe el flujo de la escena en varias ocasiones para intercalar con otros testimonios, lo que permite otorgarle al relato una carga metonímica: la historia de Claudia, si bien particular, es una demasiado habitual y por tanto la excede; la conclusión que se desprende de la secuencia es que el problema de la discriminación puede resolverse meramente a través del conocimiento.

El otro eje sobre el que se centra el documental son los estereotipos culturales alrededor de las lesbianas, y en este sentido resulta clave una vez más tanto la elección de los personajes como las acciones presentadas. El caso de Mónica es el más claro ya que su bobby es el fútbol, por lo que se la presenta en varias escenas jugando y oficiando de directora técnica de su equipo, además de la ya citada escena en el campo de Vélez. Ella representaría el estereotipo que postula a la lesbiana como una mujer que quiere ser hombre, cuestión sobre la que Mónica se explaya: "yo termino de jugar al fútbol y soy una persona que funciona como cualquier otra, sea cual sea mi gusto sexual. Y que me gusten las mujeres no me hace ir a jugar al fútbol. Primero me gustó ir a jugar al fútbol, después me gustaron las mujeres». En una entrevista, el director del film señalaba: "No pienso que Mónica Santino sea un estereotipo. Mónica Santino es un ser humano completo. Si ella representa a muchas lesbianas que se parecen porque juegan al fútbol, o porque usan jeans..., a mí no me preocupa. Decirle a un ser humano que es un estereotipo, como lo dijeron delante de ella, es una locura" (Bernini, Goggi y Schwarzböck, 2008, p. 193).

En una escena de corte más burlón se discute también sobre el peyorativo término tortillera: en ella Claudia prepara una tortilla, a la manera de un programa televisivo de cocina, mientras comenta que no entiende cuál es el significado de la palabra, más allá del insulto. En este punto se alterna con Mónica, quien explica que significa «darte vuelta de lo normal» y que ella lo utiliza en forma de chiste como un mecanismo de defensa.

Como mencionamos, el film persigue una búsqueda de identificación con el público general, motivo por el que prioriza los aspectos sentimentales y familiares, dejando de lado las historias de militancia de las protagonistas. Sobre este asunto resulta clave la escena en la que se las muestra a Claudia y a otras chicas durante/ la Marcha del Orgullo LGBT -momento en el que estos colectivos obtienen protagonismo en las calles y por lo tanto visibilidad social-, y que el film contrapone con el testimonio de Mónica (fig. 3 y 4). Ubicada en un bar, una vez más sola, expone no estar de acuerdo con estas manifestaciones y explica que:

Una marcha copiada de lo que significa en estos países, en otro contexto o en otra historia, a mi modo de ver me parece completamente contraproducente. Creo que no

3. El Instituto Nacional contra la Discriminación, la Xenofobia y el Racismo es un organismo nacional del Estado creado para combatir la discriminación. 
conduce o no tiene ninguna estrategia para conseguir lo que buscamos, que supuestamente es, a mi modo de ver, la integración y los mismos derechos porque no somos personas diferentes a otras. La idea que da para el común de la gente es agrandar la brecha (...) Yo no tengo nada para festejar, mientras las condiciones sociales sean estas (...) No creo que el común de la gente hoy se sienta representada por esta marcha.

Fig. 3 y 4: Lesbianas de Buenos Aires

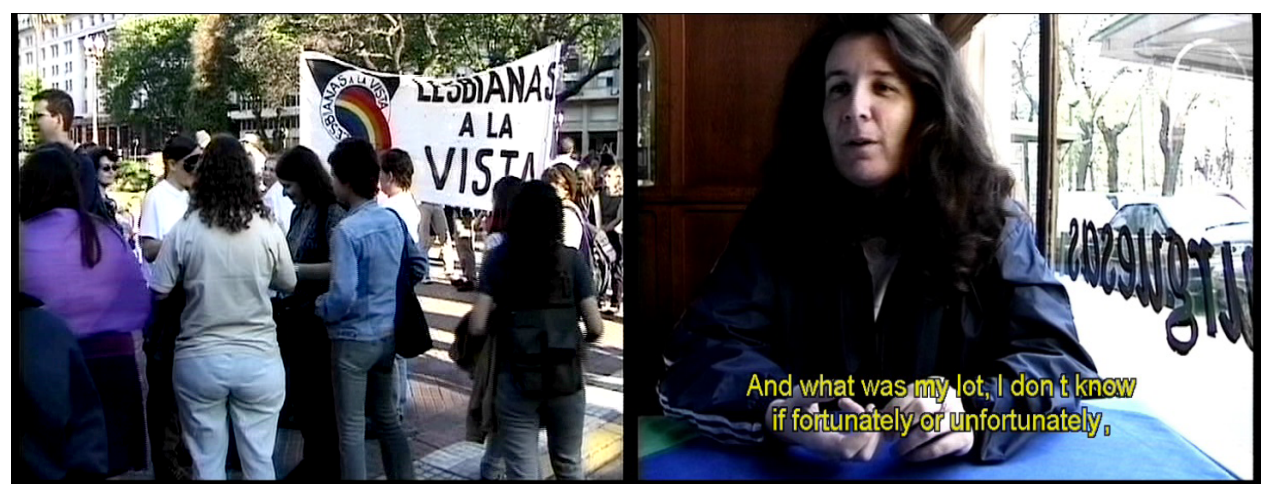

Sumado al protagonismo que se le otorga a este personaje a lo largo del film mediante la puesta en escena, en esta escena asume el rol de personaje embrague, en tanto es portavoz de las ideas del realizador (Hamon, 1977). Su discurso es interrumpido varias veces por las imágenes del resto participando en la marcha, pero no se le otorga voz a ninguna de ellas: de esta forma la escena adquiere sentido a través de las palabras de Mónica únicamente. El director exponía en una entrevista que la esencia de la película era «que el discurso político más poderoso iba a ser el discurso de las emociones y de los sentimientos y de la búsqueda de la felicidad» (Villegas, 2004, p. 26). Si bien su posición es válida, se plantea una problemática ética al mostrar a este conjunto de personajes como contrapunto de la opinión de su protagonista (y del film) sin la posibilidad de escuchar sus ideas.

Por último, según el director, las lesbianas constituyen el objeto de una «doble segregación", por su condición de mujeres y homosexuales (Bernini, Goggi y Schwarzböck, 2008, p. 190). En este sentido el documental plantea una contradicción que no logra resolver: con el objetivo de otorgarles visibilidad se les cede una presencia absoluta, la cual corre el riesgo de aislarlas de la sociedad. A su vez, la estrategia del documental radica en el borramiento de las diferencias de las minorías, pero la misma temática supone una forma de discriminar, en tanto se refiere a un colectivo, las «lesbianas de Buenos Aires», cuestión de la que da cuenta la misma Mónica cuando dice que "para discriminar siempre es bueno tender a uniformar" ${ }^{4}$.

4. Otra cuestión para mencionar es que los nombres de las participantes no figuran en ningún momento del documental, ya sea durante las entrevistas o en los créditos, lo que constituye otra forma de invisibilización. Si bien no hay trabajos sobre la recepción de las lesbianas sobre el film, en una entrevista su realizador resaltó que la mayor resistencia al título estuvo dada por las propias lesbianas (Bernini, Goggi y Schwarzböck, 2008, p. 191). 
Una de las figuras centrales, si bien relativamente desconocida, que ha trabajado en films de minorías sexuales es Maximiliano Pelosi, quien cuenta con dos documentales bajo su dirección, Otro entre otros (2009) y Una familia gay (2013), pero también con créditos de productor en Lesbianas de Buenos Aires y films de ficción sobre la temática como Un año sin amor (Anahí Berneri, 2004). Los dos documentales de su autoría proponen distintos acercamientos, tanto temáticos como estilísticos, por lo que nos ocuparemos de Una familia gay en el último apartado de este artículo. Otro entre otros se centra en una idea similar a la de Lesbianas de Buenos Aires: la doble segregación, en este caso se trata de la discriminación de la que son objeto los homosexuales dentro de la comunidad judía. El film se articula en torno a los testimonios de cuatro personajes, miembros de la comunidad Judíos Argentinos Gays (JAG), y sus historias de vida. Todos los personajes son presentados mediante un mismo procedimiento: primero se escucha su voz en off mientras se los ve recorriendo espacios cotidianos, para confluir imagen y sonido en la entrevista. Los personajes son retratados de forma frontal en un ámbito que los define: un estudio de trabajo o una sala de teatro (fig. 5), por ejemplo. Entre la presentación de cada personaje se exhiben placas sobre un fondo negro que van sumando estadísticas: "En Argentina hay 40.000.000 de habitantes. / 250.000 son judíos. Por estadística se calcula que entre un 6 y un $8 \%$ son gays. / Es decir, al menos 15.000 personas. / Si tomamos a sus grupos familiares este tema compromete al menos a 60.000 personas». Este procedimiento permite ubicar a los personajes en un contexto social y le da cuerpo a los números que tienden a ser imparciales, pero a su vez refleja la segmentación de la que se ocupa el documental.

Fig. 5: Otro entre otros

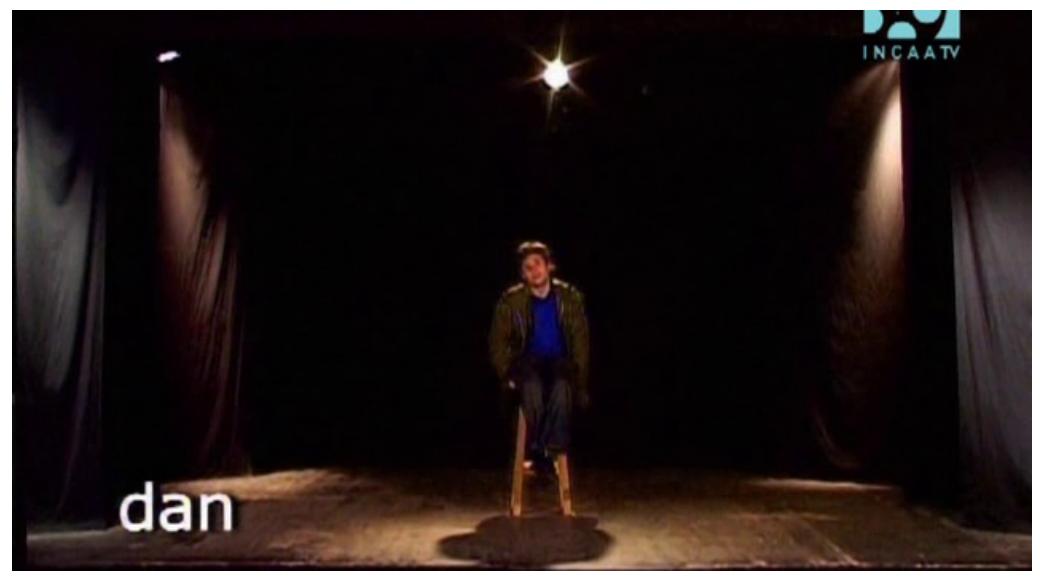

Al igual que en Lesbianas de Buenos Aires, se prioriza una vez más el relato de un sujeto, Gustavo Michanie, quien ofrece la historia más emotiva del conjunto. Alrededor de él se configuran personajes secundarios, como la madre y sus amigos que narran de forma conjunta sus reacciones cuando Gustavo les confirmó que era homosexual y cómo vencieron sus prejuicios. A pesar de que todos los participantes cuentan sus experiencias, sólo en el caso de Gustavo se apelan a testimonios de conocidos, aspecto que resalta su protagonismo al igual que el de Mónica en Lesbianas de Buenos Aires. Cada uno de los relatos se presenta de una manera visual 
bastante dinámica, uniendo a los testimonios con múltiples archivos personales, principalmente fotografías exhibidas en forma de collage que permiten ilustrar la vida de los personajes (fig. 6).

Fig. 6: Otro entre otros

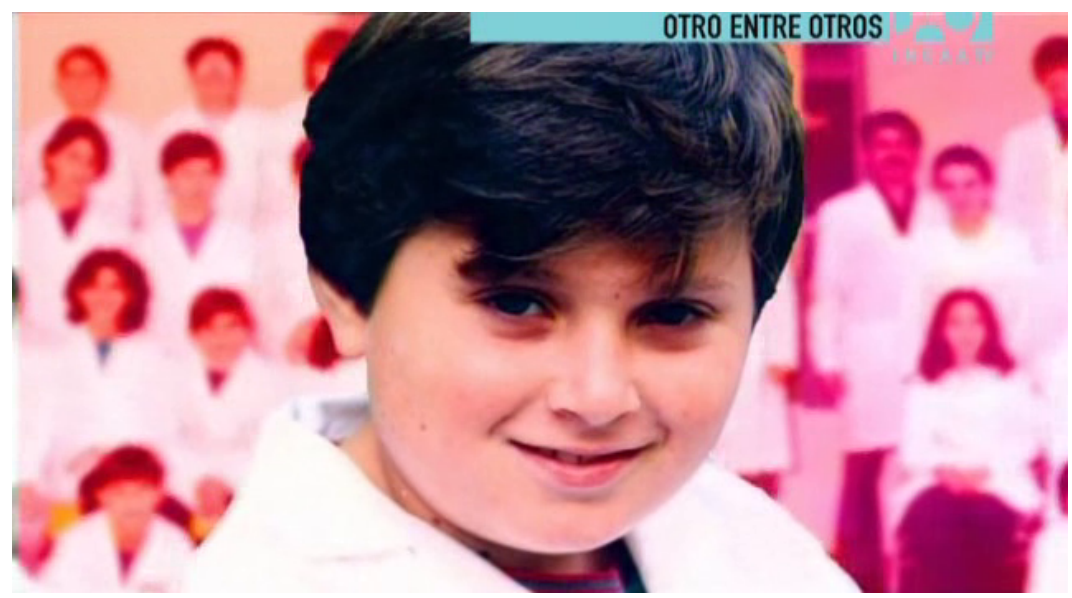

Narrativamente el film adopta el modelo biográfico, los cuatro testimoniantes van relatando su vida de forma cronológica, comenzando por la infancia, las relaciones con sus familiares, los primeros amores. Los tópicos tocados son los mismos, pero los detalles de las historias van variando (en algunos casos hay aceptación familiar, en otros no, etcétera). Siguiendo el modelo de Lesbianas de Buenos Aires se busca la identificación del público acentuando los aspectos emotivos de las vidas de los personajes, los momentos positivos y los negativos. Después de esta primera sección biográfica, hacia la mitad del film, se pone el foco en la discriminación que sufren dentro de la religión: en el caso de Gustavo cuenta que un rabino le sugirió ir a Israel para curarse, a lo que él respondió, "quiero vivir con mi homosexualidad dentro del judaísmo, no quiero salir de mi homosexualidad». Los personajes se encuentran rodeados en todo momento por la iconografía judía, remarcando el aspecto central que la religión tiene en sus vidas (fig. 7). A partir de este momento se introduce el activismo de los personajes y la creación de la JAG, desde el cual se conectan las historias individuales. La lucha por los derechos es representada mediante imágenes de la Marcha del Orgullo, gracias a las cuales consiguieron el apoyo de la Fundación Judaica, representada en el film por el testimonio de un rabino. Pero el carácter de militantes de los personajes no es el que prima, sino que esta secuencia que pone el acento en este aspecto de los personajes ocupa un lugar breve. El final del film vuelve sobre la vida de Gustavo y la muerte de su pareja, portador del virus HIV. Este relato se articula en relación con la caracterización principal de los personajes, su pertenencia a la religión, ya que Gustavo comenta que no pudo llevar a cabo su deseo: casarse según la tradición judía. 


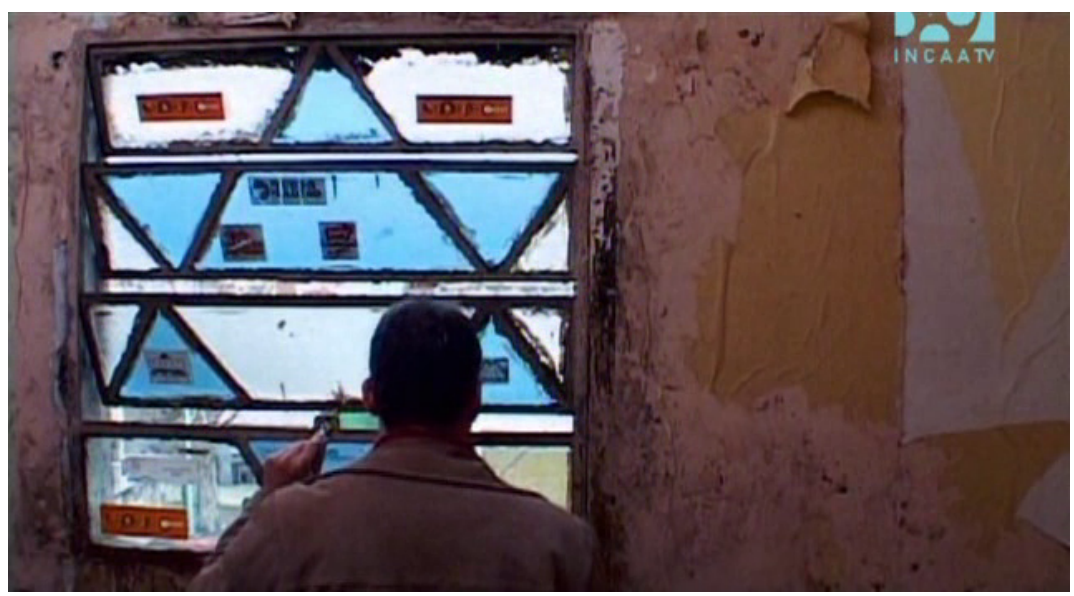

El último film de este apartado, Familias por igual (Rodolfo Moro, 2012) se centra en la discusión en torno a la conformación de familias homoparentales entablada después de la aprobación de la Ley de matrimonio igualitario. Como el título adelanta, el documental aboga por la igualdad y, si bien se apela nuevamente al uso del testimonio como herramienta principal, en este caso se pueden distinguir claramente a los testimoniantes, que narran sus historias de vida, de los entrevistados, figuras especialistas en la temática. Estos últimos, mayormente profesionales (abogados, periodistas, diputados), son revestidos de autoridad mediante la puesta en escena: retratados en sus lugares de trabajo con ciertos objetos como libros de derecho sobre una mesa mientras desarrollan la problemática a tratar (fig. 8).

Fig. 8: Familias por igual

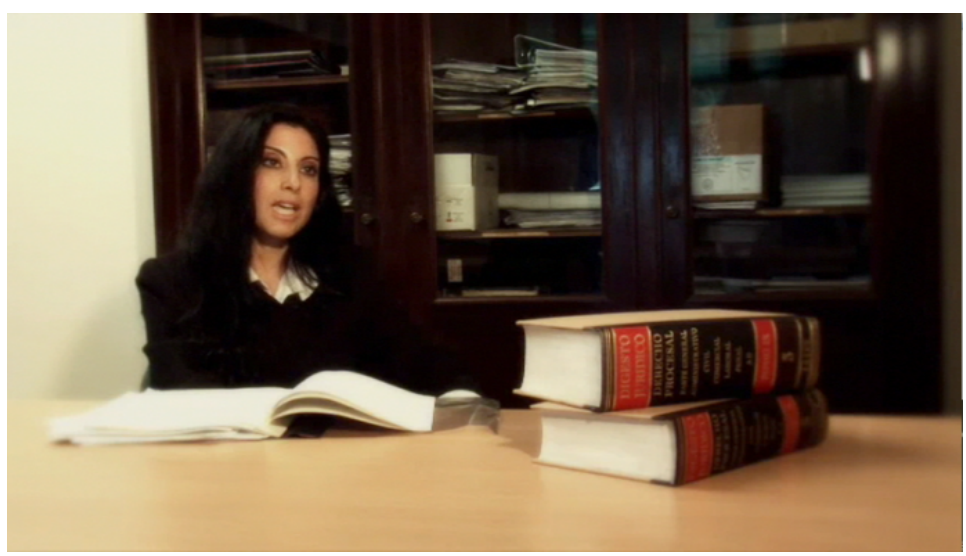

Tras estas exposiciones, los testimonios relevan a los entrevistados y sus historias funcionan a modo de demostración: entre los casos se presenta a una pareja lesbiana que pudo casarse después de tres décadas de vida en familia, la adopción de un niño 
por un hombre homosexual soltero, una pareja de lesbianas que no puede concebir y aboga por la maternidad subrogada, etcétera. En todos los testimonios se intentan enfatizar los aspectos emotivos, empleando una música melodramática omnipresente, a la vez que presentan pequeñas escenas idílicas sin diálogos que muestran a las distintas familias en plazas (fig. 9). Esta forma de presentación tiende a equiparar todos los relatos, restándoles individualidad a los personajes.

Fig. 9: Familias por igual

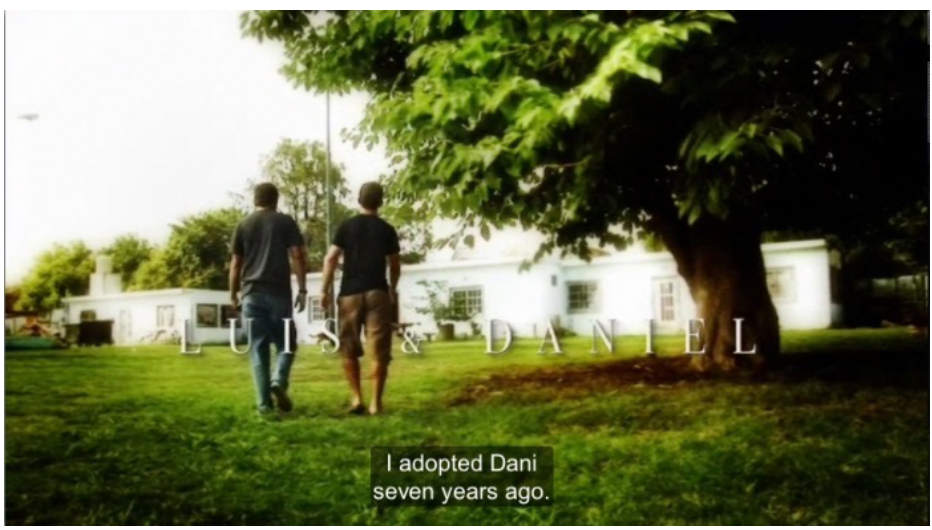

Estos tres documentales se construyen principalmente sobre el recurso de la entrevista otorgando presencia y visibilidad por primera vez en la historia del documental argentino. En este sentido, se puede argumentar que cumplen su objetivo principal, que es abogar por la semejanza de estas minorías a partir de sus historias sentimentales y el carácter pionero de visibilización de sus figuras dentro del contexto cinematográfico argentino, especialmente en el caso de Lesbianas de Buenos Aires.

Sin embargo, en todos ellos se puede observar que trabajan a partir de una categorización, una segmentación que hace mella en la idea de similitud: en el primer documental se retratan únicamente a las lesbianas, el segundo señala a una minoría dentro de otra, mientras que el último ejemplo busca meramente ilustrar todas las posibilidades. No obstante, puede discutirse los alcances de los mismos al tratarse de los primeros acercamientos a la temática suponen un valioso aporte.

\section{El pasaje de víctimas a actores sociales de las travestis}

Las travestis comenzaron a tener visibilidad social en la Argentina a mediados de la década de los noventa, con figuras como Cris Miró y Florencia de la V, ${ }^{5}$ pero se trató de casos de inserción aislados frente a la situación general que atravesaba el conjunto. Sobre este tópico se centran Hotel Gondolín (Fernando López Escrivá, 2005), el primer documental argentino sobre travestis, y Putos peronistas, cumbia del sentimiento (Rodolfo Cesatti, 2011). En ambos casos se construyen narraciones que

5. Cris Miró fue la primera actriz travesti vedette que alcanzó notoriedad mediática, rol continuado por la segunda. 
presentan una evolución de los personajes, quienes ensayan formas de protección, pasando de la denuncia al activismo y la conquista de derechos.

Hotel Gondolin se desarrolla en el ambiente del título, un hotel que tras haber sido abandonado por sus dueños se encuentra ocupado exclusivamente por travestis quienes se encargan de mantenerlo. La protagonista en este caso es Mónica León, a quien se presenta en la escena inicial despertándose en su cama mientras se escucha su voz en off. Mónica narra en las siguientes escenas desde su habitación cuándo comenzó a travestirse, que tuvo que comenzar a ejercer la prostitución en Salta a los 16 años y, mientras comparte fotos de su familia para la cámara, cuenta que tuvo que cortar esos lazos. Esta estrategia de presentación se repite con el resto de los personajes, cuyas historias prueban ser similares -todas se han visto obligadas a ejercer la prostitución y no han podido mantener relación con sus familias- y permite comprobar que la cámara mantiene una fuerte proximidad e intimidad con los sujetos dramáticos a la vez que actúan para ella (fig. 10). Las protagonistas confiesan sus ansias y angustias en off, todas señalan su (único) deseo de asumir su identidad. Mónica dice «mi mirada hacia futuro era ser travesti, definirme y nada más» y Wanda, otra de las protagonistas, es retratada en múltiples primeros planos maquillándose y afeitándose, mientras se la escucha decir: "como una mujer no me quiero ver. Yo quiero ser un travesti». Esta diferencia señalada por Wanda no es retomada en el resto del film, el conflicto del film será el lugar que ocupan en la sociedad y sus estrategias para la supervivencia.

Fig. 10: Hotel Gondolín

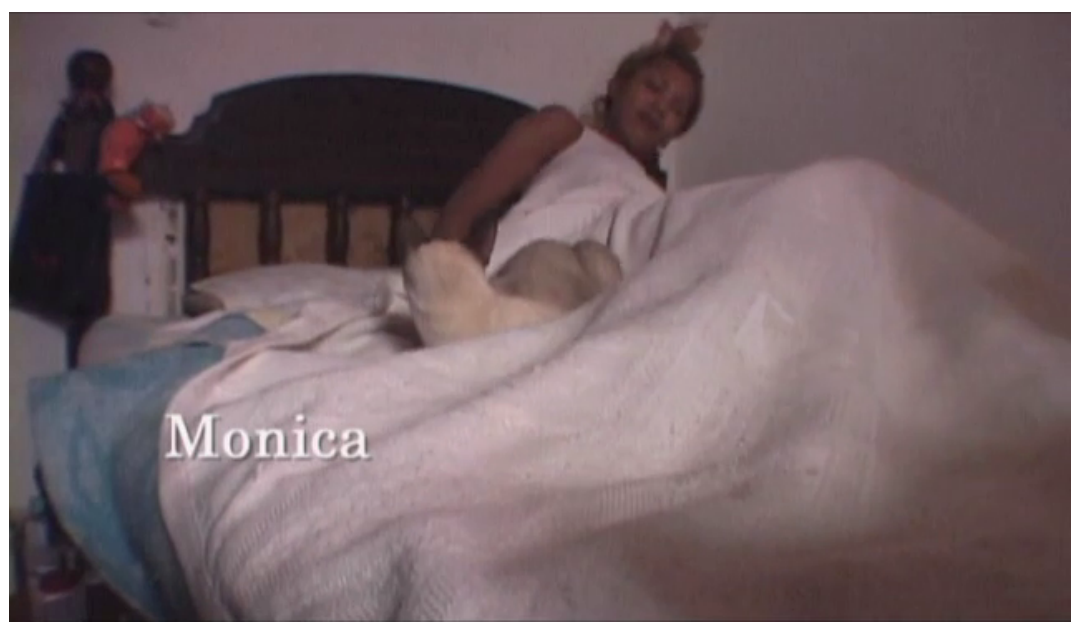

En una corta escena sin diálogos, que funciona a manera de separador, se las muestra de noche en la calle esperando clientes. Ante la llegada de un patrullero se esconden brevemente para finalmente desaparecer cuando llega el amanecer dejando lugar a los barrenderos y el comienzo de las actividades cotidianas de los vecinos. En este sentido, el espacio del hotel donde pasan sus días señala el aislamiento y la invisibilidad a las que la sociedad las confina.

La narración va revelando de a poco los planes de Mónica, que considera al hotel un albergue y proyecta armar una especie de cooperativa: se la muestra inscribiendo 
a los nuevos huéspedes en una planilla, a quienes reparte preservativos y ofrece una habitación que define como "casi un calabozo", aunque añade que es mejor que ser indigente. Durante varias reuniones presididas por Mónica se exponen las reglas de la organización, se cobra un pequeño monto por ocupar el hotel y se aplican multas a quienes consumen drogas. Este problema es uno de los principales para Mónica, quien en una entrevista cuenta que cuando llegó al hotel en 2003 «las chicas estaban fundidas con pasta base. Ninguna iba al médico, ninguna se controlaba. Adictas a la droga y andá a decirles algo. Como que el mundo les dio la espalda y ellas no forman parte de este mundo. Así que siguen sus últimos días en este mundo con su droguita y listo". Mientras se escuchan estas palabras se muestran imágenes de Wanda y otros personajes en sus camas consumiendo drogas y deprimidas, confirmando el discurso de la protagonista (fig. 11).

Fig. 11: Hotel Gondolín

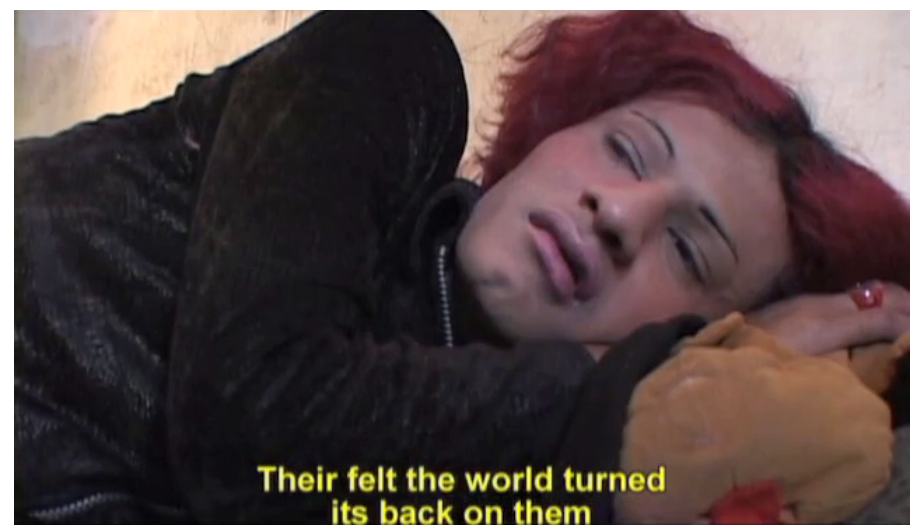

El conflicto central del film se desarrolla alrededor de la posible sanción de una nueva ordenanza sobre el Código de convivencia para delimitar el «área de trabajo sexual», que restringiría aún más las posibilidades de supervivencia del colectivo. Las posibles consecuencias de la nueva ordenanza son explicadas en una charla en el hotel con la presencia de un integrante de la CHA, indicando que su lucha forma parte de un movimiento mayor. En la audiencia pública que discute el tema, Mónica toma la palabra articulando una defensa de la identidad - "mi nombre legal será Martín Benito León, pero mi nombre real es Mónica León, como todos me conocen» (fig. 12) - y reclama derechos civiles: un marco legal que las represente, un documento de identidad que respete su identidad y la derogación del artículo 71 del Código de Convivencia Urbana que pena el trabajo sexual. En la última secuencia del film, las protagonistas expresan sus deseos para el futuro, principalmente poder llevar una vida digna, una casa, un negocio, hijos, pero señalan que para que esto sea posible deberían ser consideradas personas y "para eso faltan años" ${ }^{6}$.

6. El film concluye con un cartel que indica que «La legislatura de la Ciudad de Buenos Aires aprobó la modificación del Código Contravencional. La oferta y demanda de sexo en la vía pública está prohibida si se produce a menos de 200 metros de viviendas, escuelas o templos, lo que incluye prácticamente toda la ciudad, quedando por descarte los grandes espacios verdes como los 
Fig. 12: Hotel Gondolín

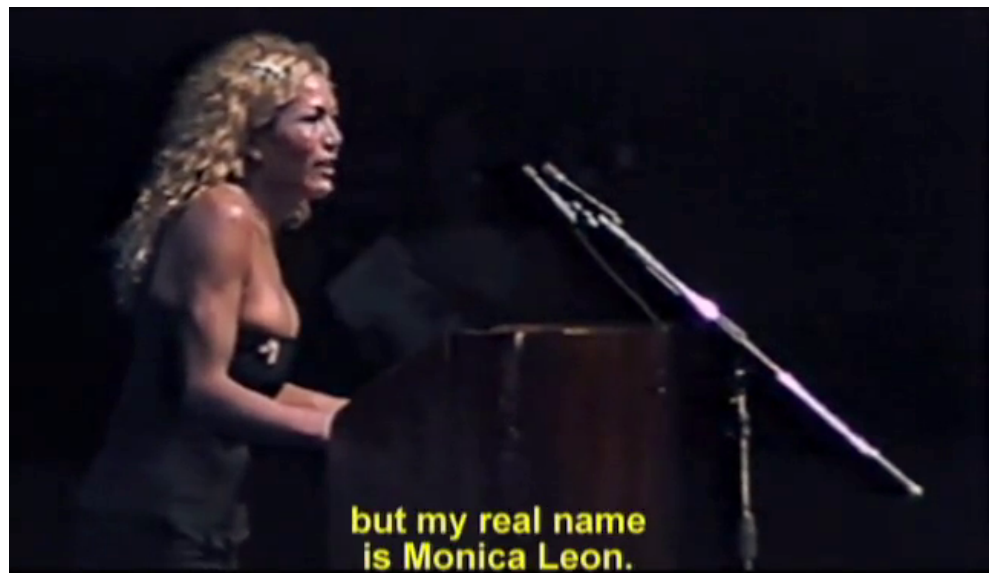

Hotel Gondolín esboza su denuncia de la situación a la que la sociedad somete a las travestis, mientras sus personajes abogan por la socialización y sus derechos como ciudadanas, a la vez que asumen la responsabilidad de la lucha por sí mismas. El documental Putos peronistas, cumbia del sentimiento retrata justamente los triunfos conseguidos durante los gobiernos de Néstor Kirchner (2003-2007) y Cristina Fernández de Kirchner (2007-2015) sobre estos mismos puntos. El film de Rodolfo Cesatti se centra en la agrupación Putos Peronistas, conformada en la localidad bonaerense de La Matanza que incluye a personas homosexuales, travestis y trans, y las actividades que llevaron a cabo durante el período 2007-2011. El principal atributo de los personajes ya no es únicamente su sexualidad, sino su condición de militantes, de actores políticos. La protagonista es una travesti, Iara Otonel, personaje que atraviesa una evolución narrativa, funcionando como símbolo de los derechos ganados por el movimiento de la diversidad sexual. El comienzo del documental introduce a la protagonista prostituyéndose en la ruta mientras se superpone en off el audio de un discurso de Juan Domingo Perón (fig. 13) ${ }^{7}$ En este momento llega uno de sus compañeros y le muestra unas fotos impresas de las primeras manifestaciones de la agrupación, de las que fue fundadora, y le comenta sobre la posibilidad de un trabajo en un Ministerio que le permitiría salir de la calle.

bosques de Palermo. Por el momento, ninguna ley o proyecto fue creado para integrar socialmente a las travestis".

7. «Cada argentino piense como piense y sienta como sienta, tiene el derecho inalienable de vivir en seguridad y pacíficamente». Extracto del discurso pronunciado por Juan Domingo Perón el 21 de junio de 1973. 
Fig. 13: Putos peronistas, cumbia del sentimiento

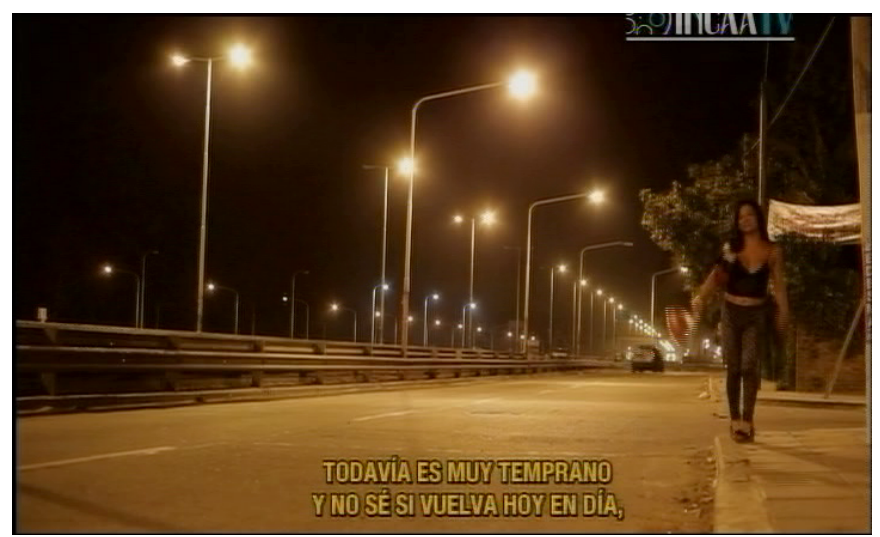

Estas primeras secuencias exponen las ideas de los Putos Peronistas en reuniones donde se suman integrantes y se planean actividades a realizar. Una de las escenas más importantes en esta sección inicial retrata una fiesta en un boliche, en la que la performance de una travesti vestida como Eva Perón expone los principios de la agrupación (fig. 14):

Somos los Putos Peronistas, nosotros representamos al pobre, al homosexual de barrio que tiene sobre sí una doble condena: por un lado, su condición de pobre y además su condición sexual. Somos los peluqueros, somos los pantaloneros, somos las tortas, las travas con siliconas baratas y las transexuales sin identidad. ¡Somos peronistas! (...) Creemos firmemente en una frase que dio el origen a esta nueva línea peronista, a estos putos peronistas, y es que hay una sola verdad mis queridos: ¡El puto es peronista y el gay es gorila!

Fig. 14: Putos peronistas, cumbia del sentimiento

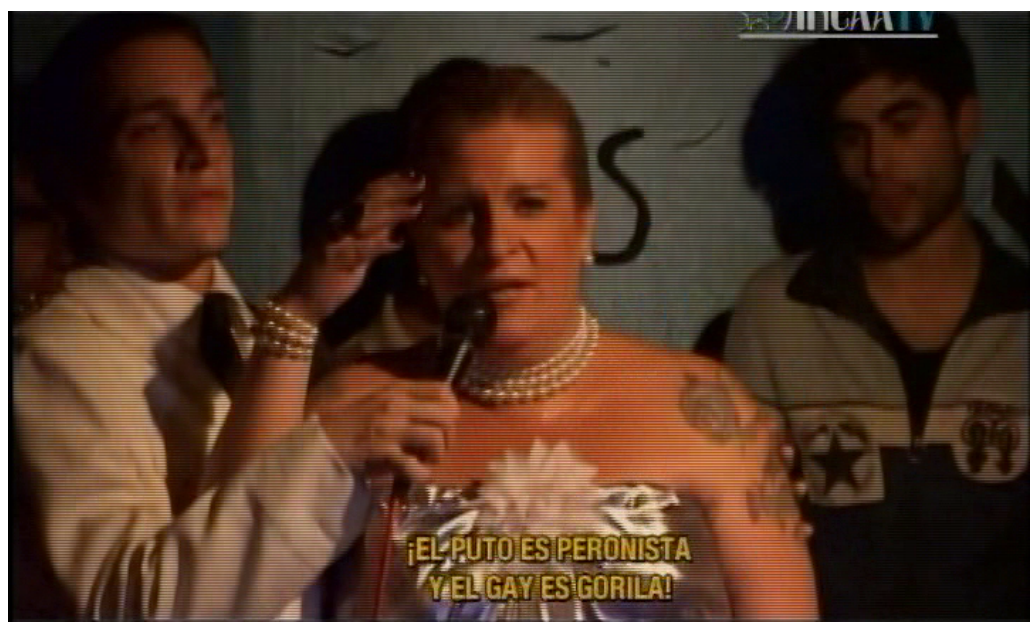


Los personajes expresan su exclusión tanto por su identidad sexual como por su condición social, y de esta manera se definen atravesados por la política, proponiéndose como herederos de la lucha comenzada por el FLH durante los años sesenta y setenta.

Toda la primera sección del film presenta la organización inicial de la agrupación y sus problemas cotidianos -que incluye amenazas en la ruta- hasta llegar a su presentación pública en la Marcha del Orgullo en 2008. Sin embargo, después de esta escena, toda la sección media del documental presenta imágenes de las distintas marchas en las que participan, manifestando su adhesión al partido político Frente para la Victoria. Si bien esta decisión respeta las acciones de los personajes, en términos dramáticos termina quitándole protagonismo ya que pasan a ser casi actores secundarios. El film deja de lado las reuniones y las discusiones de la primera mitad y pasar a ser una enumeración de los hitos del gobierno de Cristina Fernández de Kirchner y su partido Frente para la Victoria: después de la Marcha del Orgullo se pasa a la sanción de la Ley de Medios, el Matrimonio Igualitario e incluso la muerte de Néstor Kirchner. Todos estos momentos se presentan mediante carteles y consisten en breves fragmentos de declaraciones de la multitud de asistentes, tanto de miembros de la agrupación del título como de opositores. De esta manera, la lucha queda en manos de los representantes políticos y la militancia de la agrupación se convierte en un sostén.

En la última secuencia que retrata una nueva Marcha del Orgullo bajo la consigna de la identidad de género se le devuelve el protagonismo a la agrupación y es aquí donde el personaje de Iara se erige como un símbolo de las conquistas del período. Para comprender mejor cómo se construye este protagónico debemos considerar los parámetros que Carl Plantinga (1997) propone para el análisis del discurso documental, en especial el ordenamiento de los materiales y lo que el autor llama "estructura de información". Según esta propuesta es necesario "poner particular atención en el principio y final de una película, ya que muchas veces ahí es donde el discurso sugiere un esquema dominante para dirigir y asistir en la interpretación y la comprensión" (Plantinga, 1997, p. 130). En el caso de Putos peronistas la apertura y la clausura del documental le pertenece a Iara. La primera escena presentaba a Iara en la calle en situación de prostitución, por el contrario, la final la muestra otorgando un discurso frente una multitud ante la sanción de la ley de Matrimonio Igualitario: «Estamos cansadas de derramar sangre sobre el asfalto. Queremos trabajo, queremos vivir dignamente. Gracias a este gobierno, gracias a Kirchner. ¡Viva Perón carajo!» (fig. 15). El personaje de Iara atraviesa así una evolución convirtiéndose en un actor político, asumiendo su identidad y escalando socialmente, tal como indica la placa final que señala que «el 9 de mayo de 2012 el Congreso Nacional aprobó la Ley de Identidad de Género. 'La Iara' es ahora Iara Otonel, dejó la ruta y trabaja para el Ministerio de Justicia de la Nación". 
Fig. 15: Putos peronistas, cumbia del sentimiento

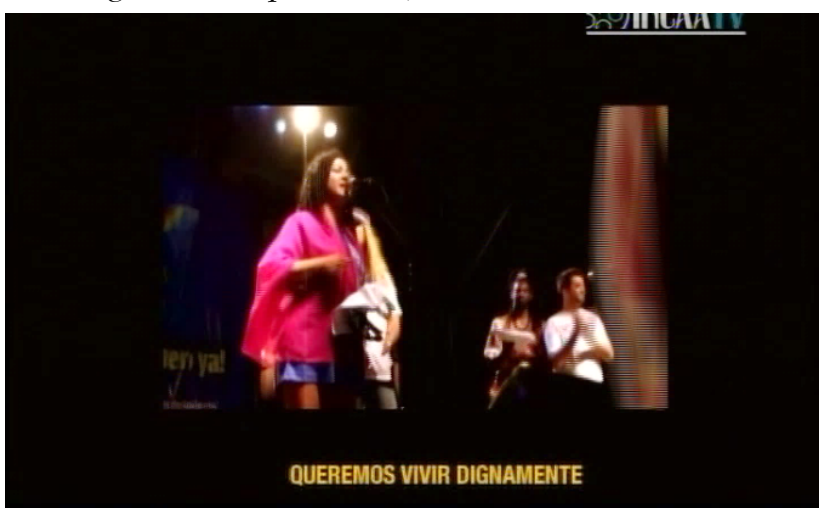

A diferencia de los documentales previos, Hotel Gondolin y Putos peronistas, retratan la búsqueda de visibilidad y la lucha por la igualdad de derechos, pero esta es abordada a través de las acciones de los mismos personajes. En ambos casos las narraciones propuestas señalan una evolución en los personajes principales, que asumen la lucha a través de la organización, si bien con distintos resultados.

\section{La identidad como construcción}

Hasta aquí la mayoría de los documentales sobre las minorías sexuales se centraron en las luchas por la visibilidad y la obtención de los mismos derechos civiles de los que goza el resto de la sociedad. Una última temática alrededor de las minorías de la producción argentina pone el foco en las estrategias de construcción de la identidad, punto que aparecía de sólo de forma tangencial en ciertas escenas de Putos peronistas y Hotel Gondolín. Una familia gay (Maximiliano Pelosi, 2013) y Camila desde el alma (Norma Fernández, 2011) abordan la sexualidad a partir de la pregunta por la igualdad de distintas maneras, pero en ambos casos se recurren a elementos performativos que no buscan poner en juicio la representación documental, sino que intentan discutir la heteronormatividad 8 .

Una familia gay, el segundo de los films dirigidos por Maximiliano Pelosi tras Otro entre otros, se desarrolla alrededor de la temática del matrimonio igualitario y la conformación familiar a partir de una inusual mezcla de ficción y documental. Interpretándose a sí mismo -o a una versión de sí-, el realizador plantea el dilema del personaje alrededor de sus dudas sobre el casamiento. El film propone una estructura narrativa sencilla utilizando como catalizador la llegada de una carta de invitación a la boda de unos amigos de la pareja protagónica; el personaje Pelosi se pregunta entonces, a través de un relato en voz off, qué significa formar una familia, interrogante que no se había planteado previamente dada la imposibilidad del matrimonio homosexual.

8. Moreno define a la heteronormatividad como «la institucionalización de la heterosexualidad como categoría universal, coherente, natural y estable, que funciona como patrón de prácticas y sentidos sexuales, relaciones afectivas y modos de ser y estar en el mundo» (2008, p. 217). Según la misma sólo existen dos identidades sexuales verdaderas: hombre y mujer. 
Para intentar llegar a una resolución el documental retrata la investigación que el personaje lleva a cabo a través de distintas entrevistas.

Los aspectos ficcionales y los documentales en Una familia gay son, en principio, distinguibles y suelen alternarse. Las escenas de ficción corresponden a la de la vida en pareja, en las que el compañero del protagonista es interpretado por el actor Luciano Linardi. ${ }^{9}$ El carácter ficcional de las mismas se revela, por un lado, por el alto nivel de intimidad de los momentos que retratan, entre ellas una escena de sexo entre la pareja y un tercero que conocen vía un website (fig. 16), y por otro lado, por su puesta en escena clásica que apela a un narrador invisible.

Fig. 16: Una familia gay

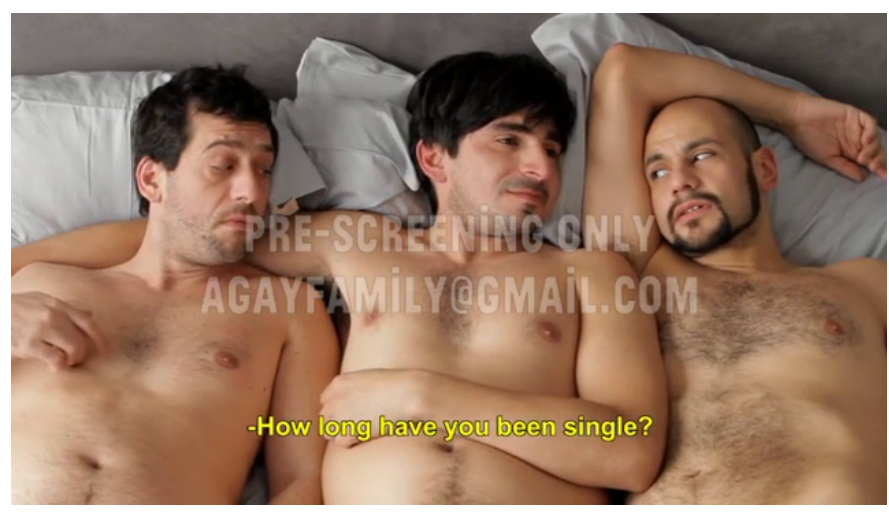

Por el contrario, las escenas documentales consisten en entrevistas en las que distintas parejas cuentan sus historias de vida, las cuales, como hemos mencionado, están articuladas dentro del marco narrativo de ficción. Los testimonios presentan un gran abanico de casos: un viudo que cuenta que se casó expresamente por el deseo de su compañero, activistas reconocidos como César Cigliutti (presidente del CHA), una pareja de mujeres que logró concebir un hijo mediante inseminación artificial, y charlas entre miembros del JAG, en las que se encuentra Gustavo, el protagonista de Otro entre otros. En ellas no se distingue entre testimonio y entrevista, sino que estos roles se conjugan, como en el caso de la hermana abogada de Pelosi, quien es la encargada de definir las obligaciones básicas del matrimonio (alimentos, asistencia y fidelidad). Los testimonios expresan diferentes puntos de vista sobre la temática, el amigo viudo reflexiona que «el matrimonio es una institución que se ha hecho para un hombre y una mujer en la sociedad heterosexual y nosotros, creo que estamos tratando de imitar ese matrimonio de una sociedad que nos ha rechazado por cientos o miles de años", e incluso se plantean disidencias entre las parejas, como el caso de Cigliutti a quien le pregunta si volvería a casarse y éste responde afirmativamente mientras que su pareja no. El aspecto más interesante de estas entrevistas es que se encuentran inmersas en la narrativa ficcional, con los personajes interactuando con el

9. El realizador explicó que esta elección se debía a que entre la aprobación del proyecto por parte del Instituto Nacional de Cine y Artes Audiovisuales (INCAA) y la filmación del film se separó de su pareja (https://www.youtube.com/watch?v=d_T5XEpV1e0) 
director/personaje, remarcando la cuestión más performativa de las mismas (fig. 17). Una familia gay se pregunta, una vez que se aprobó el matrimonio igualitario, ¿somos todos iguales? Pelosi no termina ofreciendo una respuesta, sino distintas posiciones, pero en todas priman la importancia del reconocimiento de la diferencia y el poner en discusión la norma heteroxesual).

Fig. 17: Una familia gay

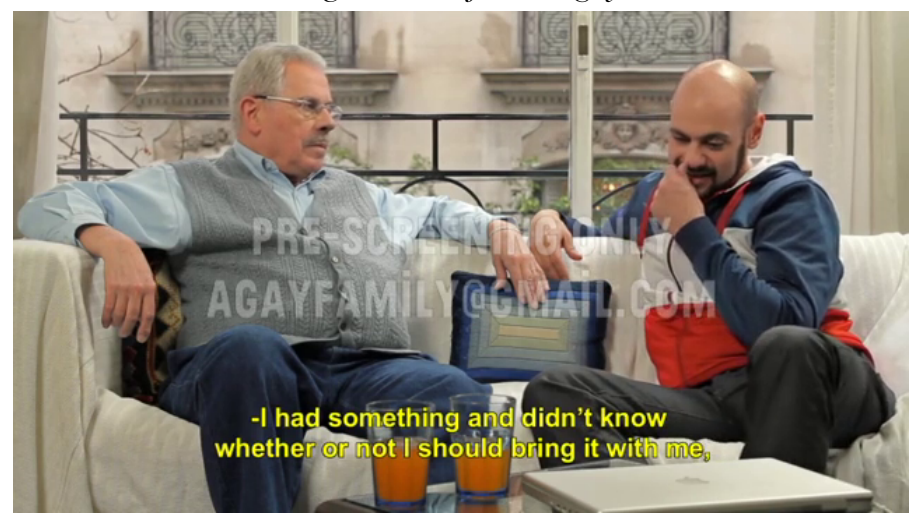

Camila, desde el alma plantea una serie de diferencias con respecto al resto de los trabajados en este texto, principalmente el carácter exclusivo que le otorga a su protagonista, la actriz travesti Camila Sosa Villalda. El film articula dos situaciones: la entrevista que conforma el grueso del documental y el registro de la representación de su obra de teatro Carnes tolendas, un biodrama en el que mezcla aspectos autobiográficos con distintos textos de Federico García Lorca (Yerma, Bodas de sangre, La casa de Bernarda Alba y Hay almas). Todo el film se construye sobre Camila, quien en la entrevista repasa su vida a la vez que comenta distintos aspectos de la obra, exhibida en fragmentos.

En la sección inicial, previa a los títulos, Camila expone las principales ideas del film a través de la lectura de uno de los textos de su obra. Primero se pregunta "¿cómo se ve un travesti a sí mismo?», y expone que es «algo innominado, con frecuencia alguien segregado, ausente de la sociedad, no reconocido, negado, negado por los padres, por la política, por la economía, por los empleadores, por la familia»; en definitiva "un ciudadano clandestino". En un primer momento el discurso de la entrevistada denuncia el rol de las travestis en la sociedad, pero luego pasa a reflexionar sobre la construcción de la identidad. Los primeros registros que se presentan de la obra muestran a Camila cambiándose de ropa, aplicando maquillaje a su rostro y uñas, operando una transformación en su cuerpo (fig. 18), a la vez que en la entrevista continúa definiendo(se) al travesti como «alguien que alguna vez franqueó su propio cuerpo, se deshizo de identidades dadas, y adoptó una esencia propia. Se es lo que se quiere ser o no se es nada». 
Fig. 18: Camila desde el alma

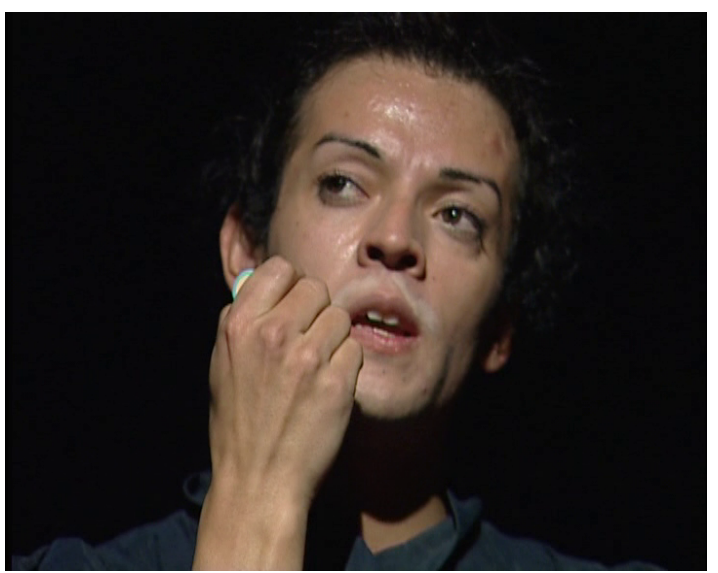

Después de esta breve escena, Camila pasa a relatar distintos aspectos de su vida que van explicando la representación teatral, principalmente la relación con sus padres. Al respecto declara que siempre se sintió más cercana a su madre (el mundo femenino) que a su padre (lo masculino), mundos que caracteriza respectivamente como "la creación, los juegos, la compañía, las risas» y «lo abusivo, la violencia, la ausencia, la dureza». En paralelo, se muestra la obra teatral donde representa tanto los papeles masculinos como femeninos, mezclando las palabras de García Lorca con textos de su autoría (fig. 19 y 20).

Fig. 19 y 20: Camila desde el alma
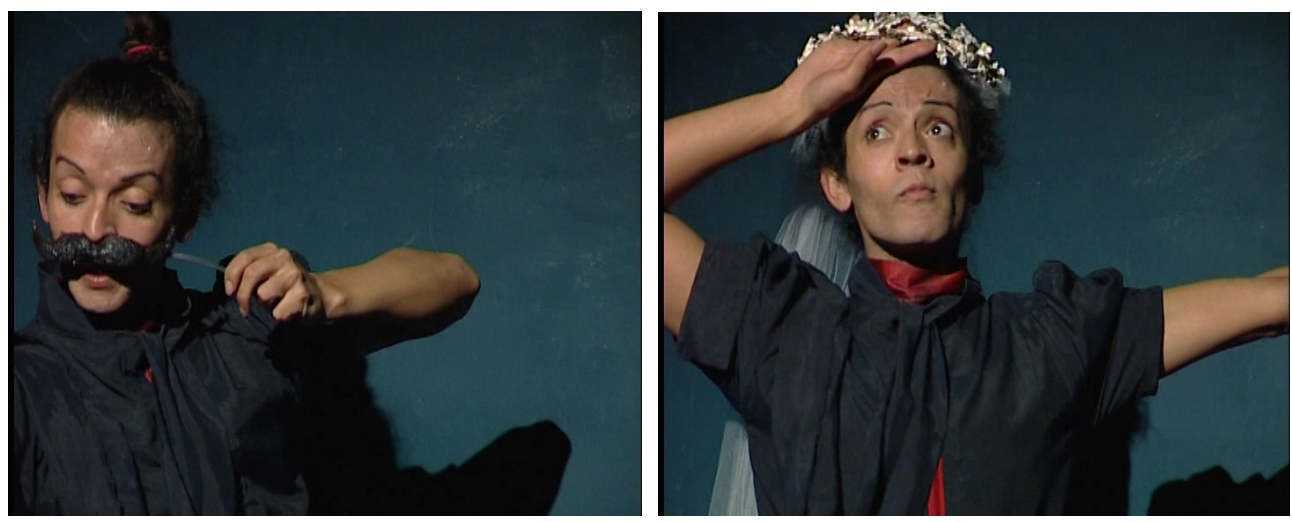

Si bien Camila desde el alma no plantea una discusión de la representación documental, ni puede ser considerado un ejemplo performativo tal como lo define Bill Nichols ${ }^{10}$, podemos hallar múltiples aspectos performativos a partir de la puesta en

10. Documentales que buscan «acentuar los aspectos subjetivos de un discurso clásicamente objetivon (Nichols, 1994, p. 95). 
escena y la presentación de la protagonista. En primer lugar, se encuentra la representación teatral, la actuación propiamente dicha asumida para un público; en segundo lugar la entrevista, instancia de creación específica para el film, reconocida como tal al desarrollarse en las gradas de la sala teatral (fig. 21). Ambas instancias pueden ser ubicadas dentro de lo que Thomas Waugh ha denominado actuaciones "presentacionales", un tipo de interpretación que evidencia "una toma de conciencia de la cámara en lugar de su ignorancia", en la que el sujeto se presenta "a uno mismo explícitamente para la cámara" (2018). ${ }^{11}$

Fig. 21: Camila desde el alma

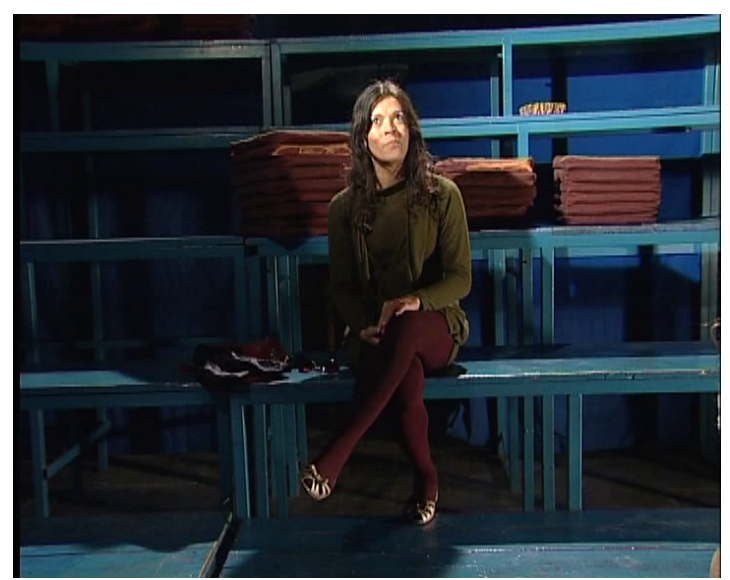

Por último, el testimonio de Camila propone a su propia identidad como una construcción, una instancia performativa. Este planteo se encuentra íntimamente ligado a la concepción del género de Judith Butler, según la cual el mismo "se construye a través de un conjunto sostenido de actos, postulados por medio de la estilización del cuerpo" (Butler, 2007, p. 17). Justamente la filósofa norteamericana apoya su teoría performativa del género sobre la acción teatral y el travestismo. La acción de género, al igual que la teatral, discurre frente a una audiencia, en este caso Camila lo hace primero para una audiencia teatral y luego para la cámara en su entrevista. Resulta necesario señalar que su obra teatral se enmarca en el género biodrama, el se busca justamente borrar los límites entre persona y personaje.

Durante su testimonio, la protagonista aboga por el reconocimiento y el derecho a la identidad, pero no dentro de las categorías prescriptivas impuestas por la heteronormatividad (hombre o mujer), sino como travesti. El documental concluye con el monólogo final de la obra teatral, en el que, tras haber transformado su apariencia, la protagonista expone:

Yo me llamo Camila y hace once años que soy travesti. Once años que me sirvieron para aprender que nunca voy a ser una mujer y nunca más volveré a ser un hombre. Usurpé

11. El otro tipo de actuación, al que Waugh llama representacional alude a la postura del sujeto actuando de forma natural, construyendo un código de ilusión narrativa documental, prestado del cine ficcional dominante. Ambas deben ser consideradas convenciones. 
el cuerpo del hombre que una vez fui, para ir matándolo poco a poco y borrar en él todo rastro de masculinidad. Una vez que lo maté, a ese cuerpo yo le di un nombre: Camila.

Precisamente, Butler aborda el travestismo para argumentar sobre el carácter performativo del género: "al imitar al género, la travestida manifiesta de forma explícita la estructura imitativa del género en sí, así como su contingencia” (Butler, 2007, p. 269). El discurso articulado por Camila se alinea así con la teoría de género butleriana.

Tanto Camila desde el alma como Una familia gay buscan discutir la igualdad de las minorías, reconociendo que el sexo y el género son culturalmente construidos (producidos) e históricamente situados. Para lograr este objetivo ambos remarcan ciertos caracteres performativos del documental y sus personajes, pero sin buscar deconstruir el discurso del cine de lo real.

\section{Conclusiones}

En este trabajo nos propusimos analizar las representaciones de la diversidad sexual en el documental argentino de las últimas dos décadas, centrándonos en cuáles fueron los mecanismos privilegiados en la construcción de los personajes y las maneras en que la misma fue evolucionando y dialogando con sus respectivos contextos.

A partir del análisis de los films seleccionados pudimos observar una tendencia a adoptar herramientas de construcción para los personajes que se repiten en varios films. Los participantes son agrupados mediante una organización categórica, es decir según una característica, en este caso su identidad sexual (lesbianas, travestis). Esta clasificación se remarca gracias a la exclusividad que los films le otorgan a cada colectivo, ya que la mayor parte del corpus no les concede voz a sujetos externos; de esta manera se favorece la construcción de personajes colectivos, aspecto remarcado por la unificación de los discursos y la ausencia de voces disonantes. Uno de los pocos ejemplos que emplea a personas por fuera de los colectivos retratados, Familias por igual, no termina de articular los testimonios y las palabras autorizadas de los entrevistados. Asimismo, pudimos reconocer la presencia de personajes protagonistas, resaltados a través de un mayor tiempo y una ubicación estratégica (al comienzo y al final), múltiples escenas en las que se los representa aisladamente y la importancia de los ambientes que ocupan.

En los últimos años se han continuado realizando documentales sobre esta temática, pero hemos podido comprobar que en el período analizado se produjo una evolución de las formas de representación y concepción de las identidades en paralelo a las discusiones oficiales y los discursos teóricos de género. Después de haber sido una temática ignorada en la filmografía nacional, se pasó de los primeros intentos de visibilización, en los que se puso el acento en remarcar las semejanzas con el resto de la sociedad, para luego remarcar las luchas emprendidas por los derechos civiles y las formas de organización de la lucha, para finalmente llegar a exponer las maneras en las que la identidad es construida, esta vez haciendo hincapié en las diferencias. 


\section{Bibliografía}

Bazán, O. (2010). Historia de la homosexualidad en la Argentina. Buenos Aires: Editorial Marea. Bellucci, M. y Rapisardi, F. (1999). Alrededor de la identidad. Las luchas políticas del presente. Nueva Sociedad, 162, pp. 40-53.

Bernini, E., Goggi, D. y Schwarzböck, S. (2008). Minorías. Conversación con Anahí Berneri, Santiago García y Pablo Pérez. Kilómetro 111. Ensayos sobre cine, 7, pp. 189-206.

Butler, J. (2007). El género en disputa. El feminismo y la subversión de la identidad. Buenos Aires: Paidós.

Melo, A. (2008). Otras historias de amor. Gays, lesbianas y travestis en el cine argentino. Buenos Aires: Ediciones Lea.

Hamon, P. (1977). Por un statut sémiologique du personnage. En Barthes, R., W. C. Booth, P. Hamon y W. Kayser. Poetique du recit. Paris: Seuil.

Moreno, Aluminé (2008). La invisibilidad como injusticia. Estrategia del movimiento de la diversidad sexual. En Mario Pecheny; Carlos Figari y Daniel Jones (comps.), Todo sexo es político. Estudios sobre sexualidades en Argentina (pp. 217-244). Buenos Aires: Libros del Zorzal.

Nichols, B. (1994). Blurred Boundaries. Bloomington: Indiana University Press.

Perlongher, N. (2008). La batalla homosexual en Argentina. En Prosa Plebeya. Ensayos 19801992 (pp. 243-248). Buenos Aires: Colihue.

Piedras, P. (2014). El cine documental en primera persona. Buenos Aires: Paidós.

Plantinga, C. (1997). Rhetoric and Representation in Nonfiction Film. New York: Cambridge University Press.

Settanni, S. (2013). Sexualidades politizadas y medios de comunicación: la Marcha del Orgullo LGBT de Buenos Aires. AVATARES de la comunicación y la cultura, $\mathrm{N}^{\circ} 5$. En http://ppct. caicyt.gov.ar/index.php/avatares/article/viewFile/3022/2914 [Fecha de consulta: 10 de octubre de 2019]

Villegas, J. (2004). Espacios de libertad. El Amante, N 149, pp. 25-26.

Waugh, T. (2018). Actuando para interpretarse a sí mismo: la interpretación en el documental. Revista Cine documental, No 18. En http://revista.cinedocumental.com.ar/actuando-para-interpretarse-a-si-mismo-la-interpretacion-en-documental/ [Fecha de consulta: 10 de octubre de 2019]

\section{Listado de films mencionados}

Adiós, Roberto (Enrique Dawi, 1984)

Otra historia de amor (Américo Ortiz de Zárate, 1986)

Lesbianas de Buenos Aires (Santiago García, 2004)

Otro entre otros (Maximiliano Pelosi, 2009)

Una familia gay (Maximiliano Pelosi, 2013)

Un año sin amor (Anahí Berneri, 2004)

Familias por igual (Rodolfo Moro, 2012)

Hotel Gondolín (Fernando López Escrivá, 2005)

Putos peronistas, cumbia del sentimiento (Rodolfo Cesatti, 2011).

Una familia gay (Maximiliano Pelosi, 2013)

Camila desde el alma (Norma Fernández, 2011) 